\title{
Pediatric Liver and Kidney Transplantation With Allografts From DCD Donors: A Review of UNOS Data
}

\author{
Peter Abt, ${ }^{1,3}$ Randeep Kashyap, ${ }^{1}$ Mark Orloff, ${ }^{1}$ Ashok Jain,,${ }^{1}$ George Tsoulfas, ${ }^{1}$ Adel Bozorgzadeh, ${ }^{1}$ \\ and Kim Olthoff ${ }^{2}$
}

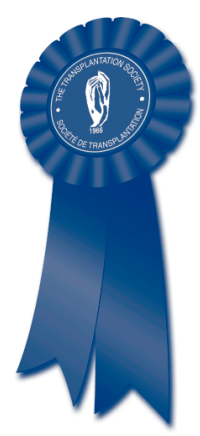

Introduction. Donation after cardiac death (DCD) is recognized as an important source of allografts to bridge the growing disequilibrium between the number of donors and recipients. Current transplant experience with DCD organs has focused on the adult recipient population, however little is known about the pediatric recipient experience. While there is increasing acceptance of these grafts in adults, transplant centers appear reluctant to use these grafts in the pediatric population.

Methods. We reviewed the United Network for Organ Sharing database from 1995-2005 to determine the national experience with pediatric recipients of DCD organs.

Results. Among 4026 renal transplants performed in children 18 years and younger, $26(0.6 \%)$ received a renal allograft from a DCD donor. Ten (38.5\%) received kidney allografts from pediatric donors (age $\leq 18)$ and 16 (61.5\%) from adult donors (age $>18$ years). Graft survival at one and five years was $82.5 \%$, 74.3\% for kidneys from DCD donors compared to $89.6 \%, 64.8 \%$ from brain dead donors (DBD) $(P=0.7)$. Among 4991 liver transplants, $19(0.4 \%)$ were from DCD donors. Sixteen patients $(84.2 \%)$ received livers from pediatric donors and three $(15.8 \%)$ from adult donors. Graft survival at one and five years was $89.2 \%, 79.3 \%$ for livers from DCD, compared to $75.6 \%$, $65.8 \%$ for $\mathrm{DBD}(P=0.3)$.

Conclusion. The use of DCD donors in the pediatric population is very limited; however graft survival is comparable to DBD grafts. Although pediatric centers may have been reluctant to utilize this donor source, this limited experience demonstrates that the select use of DCD organs can produce acceptable and durable graft survival in the pediatric population.

Keywords: Donation after cardiac death, Non-heart-beating donor, Liver transplantation, Pediatric.

(Transplantation 2006;82: 1708-1711)

O ver the last several years a growing interest has been expressed in pursuing organ donors immediately after cessation of cardiac function, as a means to increase organ availability. A recent national conference, as well as the Organ Donation Breakthrough Collaborative initiated by the Health Resources and Services Administration (HRSA) has addressed the growing experience with this type of donor. Also termed a non-heart-beating donor or donation after cardiac death (DCD), these efforts have affirmed the potential to increase organ donation $(1,2)$. The United Network for Organ Sharing (UNOS) data demonstrates the growing number of DCDs as a percentage of total organ donors. In 19951.1 per-

This work was supported in part by Health Resources and Services Administration contract 234-2005-370011C. The content is the responsibility of the authors alone and does not necessarily reflect the views or policies of the Department of Health and Human Resources, nor does mention of trade names, commercial products, or organizations imply endorsement by the U.S. Government.

${ }^{1}$ Department of Surgery, Solid Organ Transplantation and Hepatobiliary Surgery Division, University of Rochester Medical Center, Rochester, NY.

${ }^{2}$ Department of Surgery, University of Pennsylvania, Philadelphia, PA 19104, USA

${ }^{3}$ Address correspondence to: Peter Abt, M.D., Division of Solid Organ Transplantation and Hepatobiliary Surgery, Department of Surgery, University of Rochester Medical Center, 601 Elmwood Ave., Box SURGTXP, Rochester, NY 14642-8410.

E-mail: peter_abt@urmc.rochester.edu

Received 27 July 2006. Revision requested 22 August 2006.

Accepted 27 October 2006.

Copyright $\odot 2006$ by Lippincott Williams \& Wilkins

ISSN 0041-1337/06/8212-1708

DOI: 10.1097/01.tp.0000254762.95625.d0 cent of all deceased donors were categorized as DCD, which increased to 3.9 percent in 2004 (3).

In concordance, the total number of organs transplanted from DCDs has also risen, particularly among kidney and liver allografts, with a growing interest in the use of DCDs for pancreas and lung transplantation $(4,5)$. Short and long-term data with renal allografts demonstrate similar survival as organs from brain dead donors (DBD), although the incidence of delayed graft function is approximately twice that compared to $\operatorname{DBD}(6,7)$. Among liver recipients, allograft survival appears to be inferior to that from brain dead donors, although some centers have reported equivalent results. Among liver recipients there may be an increased incidence of primary non-function and biliary complications $(8-15)$.

The data regarding outcomes has primarily been based upon transplantation in adults. With the renewed interest in DCDs, the question arose as to the experience and outcomes in the pediatric population. To address this issue a query of the UNOS database was undertaken.

\section{METHODS}

The UNOS renal and liver transplant databases were examined to define donor and recipient variables among those pediatric patients who had received an allograft from a DCD. The data was limited to the years 1995 through September 2005. Recipients 18 years or less at the time of transplant were included. Graft survival was defined as the time from transplant to last follow-up, retransplant, return to dialysis, or patient death. Those patients without follow-up or who were lost to follow-up were excluded. Among liver recip- 
ients, primary nonfunction was defined as graft failure within seven days of transplant. A comparison group consisted of all pediatric recipients of a cadaveric allograft.

Means of continuous variables were compared by $t$ tests and categorical variables were compared by chi square testing. Kaplan-Meier analysis was used to compute overall graft and patient survival. Comparison of Kaplan-Meier survival between groups was performed using the log-rank statistic. Statistical analysis was performed with SPSS version 13 for Windows (SPSS Inc., Chicago, IL).

\section{RESULTS}

\section{Kidney Transplants}

During the period analyzed, 26 pediatric DCD kidney transplants took place compared to 4000 from DBDs (Table 1). Donor characteristics including cold ischemic time were similar between the groups. Mean donor age was also similar; with 38.5 percent of the donors 18 years of age or less. Discharge creatinine and delayed graft function were similar to DCD recipients (Table 3 ). Five year graft survival was $74.3 \%$, compared to $64.8 \%$ for DBD (Figure 1).

TABLE 1. Pediatric kidney transplants; recipient and donor characteristics

\begin{tabular}{|c|c|c|c|}
\hline & $\mathrm{DCD}^{a}$ & $\mathrm{DBD}^{a}$ & $P$ value \\
\hline \multicolumn{4}{|l|}{ Recipient } \\
\hline $\mathrm{N}$ & 26 & 4000 & \\
\hline Age (years) & $13.2(4.2)$ & $12.3(4.8)$ & 0.3 \\
\hline Gender (\% male) & 57.6 & 68.3 & 0.9 \\
\hline $\begin{array}{l}\text { Dialysis prior to } \\
\text { transplantation }(\%)\end{array}$ & 84.6 & 76.7 & 0.3 \\
\hline $\begin{array}{l}\text { Previous kidney } \\
\text { transplant }(\%)\end{array}$ & 23.1 & 15.2 & 0.2 \\
\hline \multicolumn{4}{|l|}{ Donor } \\
\hline Age & $24.2(14.5)$ & $25.7(14.0)$ & 0.5 \\
\hline Gender (\% male) & 73.0 & 62.5 & 0.2 \\
\hline Donor creatinine $(\mathrm{mg} / \mathrm{dL})$ & $0.9(0.4)$ & $1(0.1)$ & 0.8 \\
\hline $\begin{array}{l}\text { Warm ischemic time }{ }^{b} \\
\quad \text { (minutes) }\end{array}$ & $13.6(9.9)$ & NA & \\
\hline $\begin{array}{l}\text { Cold ischemic time } \\
\text { (hours) }\end{array}$ & $18.4(6.6)$ & $16.9(7.6)$ & 0.3 \\
\hline \multicolumn{4}{|l|}{ Organ allocation (\%) } \\
\hline Local & 88.5 & 75.3 & \\
\hline Regional & 3.8 & 8.8 & \\
\hline National & 7.7 & 15.9 & \\
\hline \multicolumn{4}{|l|}{ Cause of death (\%) } \\
\hline Anoxia & 30.8 & 11.8 & \\
\hline Cerebrovascular/stroke & 7.7 & 23.9 & \\
\hline Head trauma & 61.5 & 60.9 & \\
\hline CNS tumor & 0 & 1.0 & \\
\hline Other & 0 & 2.4 & \\
\hline
\end{tabular}

\footnotetext{
${ }^{a}$ Numbers in parenthesis represent standard deviation.

${ }^{b} \mathrm{~N}=22$ for DCD.
}

\section{Liver Transplants}

There were 19 pediatric recipients identified who received DCD liver grafts. When compared to transplants from DBDs, there was a trend toward older recipient age $(P=0.09)$, however mean donor age was not significantly different. In contrast to the renal donors, $84.2 \%$ of the DCD grafts were from donors younger than 18 (Table 2). The recipient's medical condition based upon the patient's location prior to transplant was similar between the two groups. Incidence of primary nonfunction and retransplant were similar between DCD and DBD recipients (Table 3 ). Five year graft survival was $79.3 \%$ for DCD livers compared to $65.8 \%$ for DBD (Fig. 1).

\section{DISCUSSION}

Organ donation from DCD has gained considerable attention within the last few years, as the disparity between the waitlist and donors continues to grow. The potential to increase the number of donors from this source and ameliorate the organ shortage may be substantial. Previous reports have, in general, focused upon outcomes in the adult recipient population. The current analysis was conducted to ascertain the incidence and outcome with DCD organs in the pediatric population. The national experience during the last ten years is limited, with only 26 kidney recipients and 19 liver recipients; however, the outcomes appear to compare favorably to organs from DBD donors.

Transplantation of DCD organs has primarily been to the adult population, with this type of donor usually considered an expanded criteria donor. In general organ allocation tends to favor the pediatric recipient, and understandably there is a reluctance by the pediatric transplant surgeon and physician to transplant children with organs that might be considered less desirable and have poorer long-term survival. Although long-term renal data in the adult population demonstrates outcomes similar to that of DBDs, national data is not as favorable among liver recipients $(6,7)$. Two analyses utilizing UNOS data demonstrate an approximately $10 \%$ lower graft survival among recipients of a DCD liver. Inferior graft survival persists after controlling for multiple donor and recipient variables $(11,14)$. Among recipients of a liver transplant from a DCD, there may be an increased incidence in ischemic type biliary strictures as well as primary nonfunction (10). The increased risk of poor graft function is balanced by the high rate of death on the adult waiting list for liver transplantation. Some single center reports have shown favorable outcomes with this type of donor, raising the possibility that donor selection, procurement technique, or short ischemic times could ameliorate untoward complications (9, $12,13,15)$.

A majority of the DCD kidney donors in this analysis were young adults, utilized in older children. In comparison, most liver donors were children, likely related to the necessity of matching graft to recipient size in younger children with liver disease. Recently successful split liver transplantation from DCDs into children has been reported by the group at King's College $(16,17)$.

The potential to increase the pediatric donor pool through the routine use of pediatric DCDs is attractive, but only if outcomes are also acceptable. Koogler examined this 


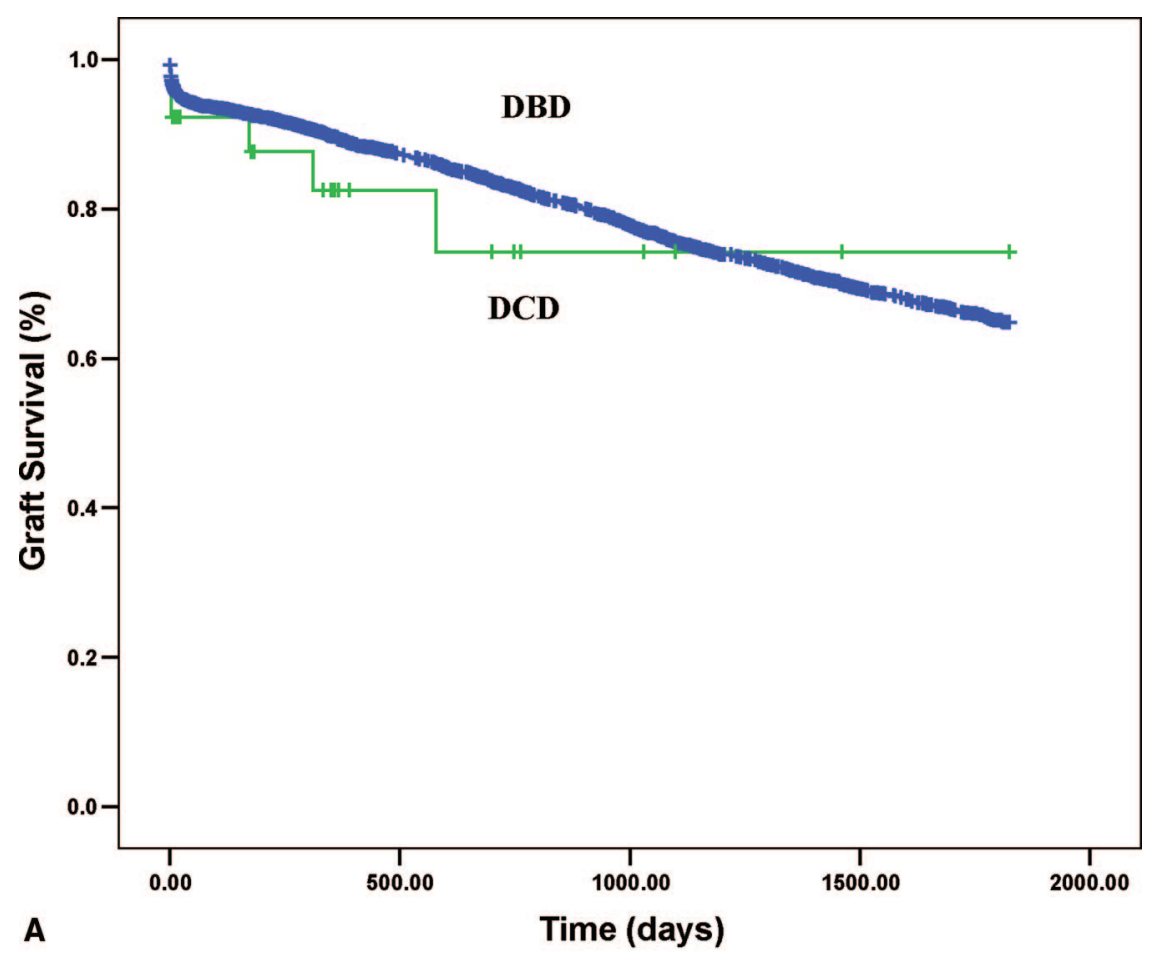

FIGURE 1. Graft survival among kidney (part A) and liver recipients (part B). Graft survival at one and five years among DCD kidney recipients was $82.5 \%$ and $74.3 \%$ vs. $89.6 \%$ and 64.8 for DBD $(P=0.7)$. For DCD liver recipients, one and five year graft survival was $89.2 \%$ and $79.3 \%$ vs. $75.6 \%$ and $65.8 \%$ for $\mathrm{DBD}(P=0.3)$.

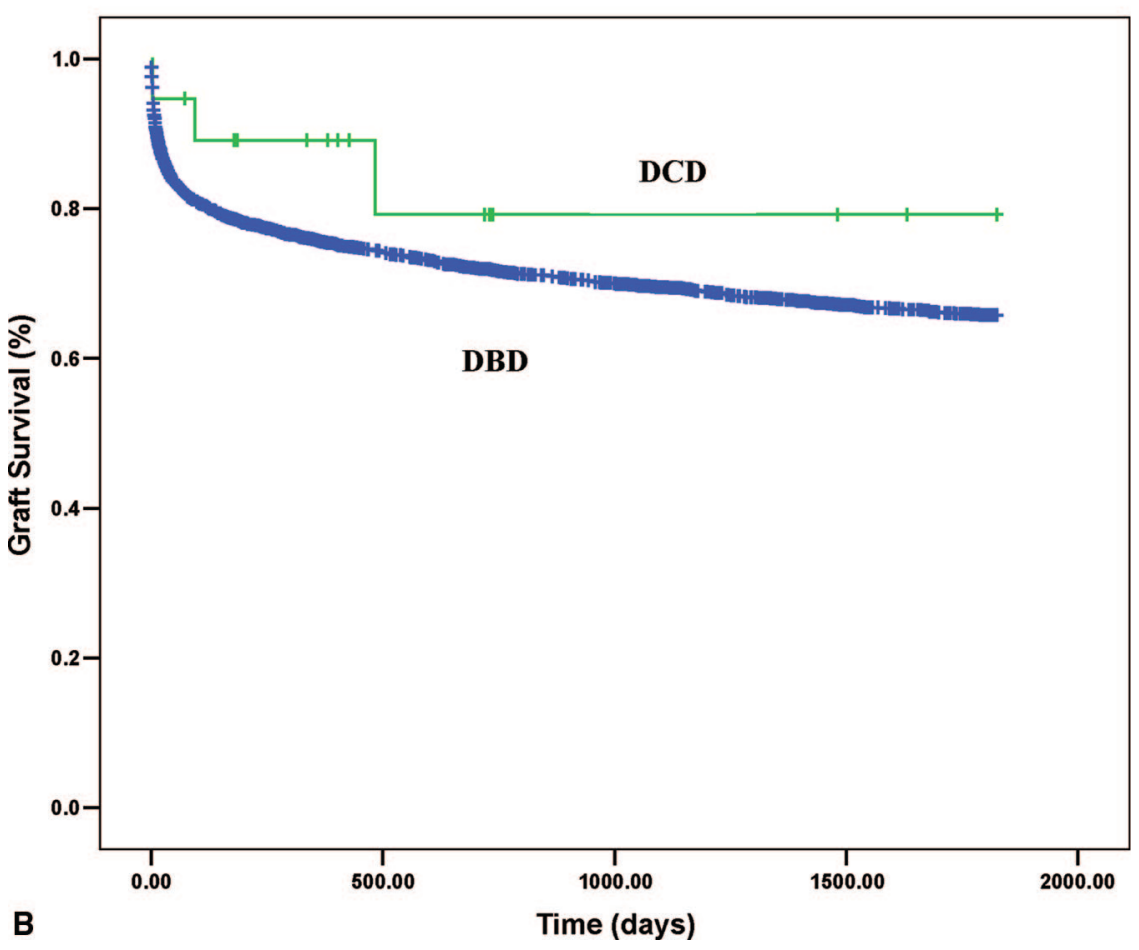

issue in a pediatric ICU, and found the potential for a $40 \%$ increase in pediatric donors (18). Estimates as to the number of increased grafts if all potential DCDs were utilized vary widely, from 11 to $350 \%(19,20)$. The variability in these estimates is dependent on the consideration of uncontrolled DCD donors. However the true potential number of donors may fall on the lower side of this estimate. In the United States, experienced organ procurement organizations with long standing DCD programs report that about $20 \%$ of cadaveric donors fall into this category (3).

Given the small size of the population in this study it is difficult to draw solid conclusions. Pediatric recipients of DCD organs appear to have results similar to recipients of DBD organs, but caution should be urged with interpretation of the data. While the data does provide some insight into the pediatric population of DCD donors and recipients, it is not 
TABLE 2. Pediatric liver transplants; recipient and donor characteristics

$\mathrm{DCD}^{a} \quad \mathrm{DBD}^{a} \quad P$ value

\begin{tabular}{|c|c|c|c|}
\hline \multicolumn{4}{|l|}{ Recipient } \\
\hline $\mathrm{N}$ & 19 & 4972 & \\
\hline Age & $8.7(7.3)$ & $5.7(6.1)$ & 0.09 \\
\hline Gender (\% male) & 63.2 & 47.1 & 0.2 \\
\hline $\begin{array}{l}\text { Pretransplant total bilibrubin } \\
\text { (mg/dL) }\end{array}$ & $7.8(8.0)$ & $11.6(12.3)$ & 0.2 \\
\hline Previous liver transplant (\%) & 21.1 & 15.5 & 0.5 \\
\hline $\begin{array}{l}\text { Medical condition at } \\
\text { transplant }(\%)^{b}\end{array}$ & & & 0.3 \\
\hline ICU & 31.6 & 32.2 & \\
\hline Hospital non-ICU & 5.2 & 17.3 & \\
\hline Home (outpatient) & 63.2 & 50.5 & \\
\hline \multicolumn{4}{|l|}{ Donor } \\
\hline Age & $12.2(14.4)$ & $13.3(14.9)$ & 0.74 \\
\hline Gender (\% male) & 57.9 & 58.0 & 0.9 \\
\hline $\begin{array}{l}\text { Warm ischemic time } \\
\quad(\text { minutes })^{c}\end{array}$ & $11.6(5.3)$ & NA & \\
\hline Cold ischemic time (hours) ${ }^{d}$ & $8.1(3.6)$ & $8.4(4.2)$ & 0.8 \\
\hline \multicolumn{4}{|l|}{ Organ allocation $(\%)^{e}$} \\
\hline Local & 68.4 & 45.5 & \\
\hline Regional & 15.8 & 34.6 & \\
\hline National & 15.8 & 19.9 & \\
\hline \multicolumn{4}{|l|}{ Cause of death $(\%)^{f}$} \\
\hline Anoxia & 36.8 & 20.5 & \\
\hline Cerebrovascular/stroke & 5.3 & 15.9 & \\
\hline Head trauma & 52.6 & 58.7 & \\
\hline CNS tumor & 0 & 0.8 & \\
\hline Other & 5.3 & 4.1 & \\
\hline
\end{tabular}

${ }^{a}$ Numbers in parenthesis represent standard deviation.

${ }^{b} \mathrm{~N}=16$ for DCD.

${ }^{c} \mathrm{~N}=18$ for DCD.

${ }^{d} \mathrm{~N}=4906$ for DBD.

${ }^{e} \mathrm{~N}=4956$ for DBD

${ }^{f} \mathrm{~N}=4939$ for DBD.

TABLE 3. Pediatric kidney and liver recipient outcome data

\begin{tabular}{lccc} 
& DCD $^{\boldsymbol{a}}$ & DBD $^{\boldsymbol{a}}$ & $\boldsymbol{P}$ value \\
\hline Kidney & & & \\
$\quad \mathrm{N}$ & 26 & 4000 & \\
$\quad$ Retransplant (\%) & 15.9 & 17.3 & 0.8 \\
$\quad$ Delayed graft function (\%) & 19.2 & 13.6 & 0.9 \\
$\quad$ Creatinine at discharge (mg/dL) & $2.3(2.0)$ & $1.7(2.0)$ & 0.1 \\
Liver & & & \\
N & 19 & 4972 & \\
Retransplant (\%) & 10.5 & 13.0 & 0.3 \\
Primary non-function (\%) & 5.3 & 7.9 & 0.6 \\
\hline
\end{tabular}

${ }^{a}$ Numbers in parenthesis represent standard deviation. able to explore some clinically relevant sources of morbidity such as biliary strictures, due to the nature of large national datasets. Despite these limitations, and although transplant centers have understandably been reluctant to use DCD organs in pediatric patients, this data suggest that with selective use and in the correct setting, liver and kidney recipients can expect durable results.

\section{REFERENCES}

1. Bernat JL, D'Alessandro AM, Port FK, et al. Report of a national conference on donation after cardiac death. Am J Transplant 2006; 6: 281.

2. U.S. Department of Health and Human Services, Organ Donation Breakthrough Collaborative. www.organdonationnow.org.

3. Scientific Registry of Transplant Recipients. www.ustransplant.org.

4. Howard RJ, Schold JD, Cornell DL. A 10-year analysis of organ donation after cardiac death in the United States. Transplantation 2005; 80: $564-8$.

5. Fernandez LA, Di Carlo A, Odorico JS, et al. Simultaneous pancreaskidney transplantation from donation after cardiac death: successful long-term outcomes. Ann Surg 2005; 242: 716.

6. Cho YW, Terasaki PI, Cecka JM, Gjertson DW. Transplantation of kidneys from donors whose hearts have stopped beating. N Engl J Med 1998; 338: 221.

7. Weber M, Dindo D, Demartines N, Ambuhl PM, Clavien PA. Kidney transplantation from donors without a heartbeat. N Engl J Med 2002; 347: 248.

8. Casavilla A, Ramirez C, Shapiro, et al. Experience with liver and kidney allografts from non-heart-beating donors. Transplant Proc 1995; 27: 2898 .

9. Manzarbeitia CY, Ortiz JA, Jeon H, et al. Long-term outcome of controlled, non-heart-beating donor liver transplantation. Transplantation 2004; 78: 211.

10. Abt P, Crawford M, Desai N, Markmann J, Olthoff K, Shaked A. Liver transplantation from controlled non-heart-beating donors: an increased incidence of biliary complications. Transplantation 2003; 75: 1659.

11. Abt PL, Desai NM, Crawford MD, et al. Survival following liver transplantation from non-heart-beating donors. Ann Surg 2004; 239: 87.

12. Muiesan, P, Girlanda R, Jassem W, et al. Single-center experience with liver transplantation from controlled non-heart-beating donors: a viable source of grafts. Ann Surg 2005; 242: 732.

13. Foley DP, Fernandez LA, Leverson G, et al. Donation after cardiac death: the University of Wisconsin experience with liver transplantation. Ann Surg 2005; 242: 724.

14. Mateo R, Cho Y, Singh G, et al. Risk factors for graft survival after liver transplantation from donation after cardiac death donors: an analysis of OPTN/UNOS data. Am J Transplant 2006; 6: 791.

15. Fukumori T, Kato T, Levi D, et. al. Use of older controlled nonheart-beating donors for liver transplantation. Transplantation 2003; 8: 1171.

16. Muiesan P, Girlanda R, Baker A, Rela M, Heaton N. Successful segmental auxiliary liver transplantation from a non-heart-beating donor: implications for split-liver transplantation. Transplantation 2003; 75: 1443 .

17. Muiesan P, Jassem W, Girlanda R, et. al. Segmental liver transplantation from non-heart beating donors - an early experience with implications for the future. A J Transplantation 2006; 6: 1012.

18. Koogler T, Costarino AT. The potential benefits of the pediatric nonheartbeating organ donor. Pediatrics 1998; 101: 1049.

19. Evans R. Kidney transplantation from donors without a heartbeat. N Eng J Med 2002; 347: 1799.

20. Kootstra G. The asystolic, or non-heartbeating, donor. Transplantation 1997; 63: 917. 